\title{
A MOLECULAR REEXAMINATION OF INTROGRESSION BETWEEN HELIANTHUS ANNUUS AND H. BOLANDERI (COMPOSITAE)
}

\author{
Loren H. Rieseberg, ' Douglas E. Soltis, \\ Department of Botany, Washington State University, Pullman, WA 99164 \\ AND \\ JEFFrey D. PALMER \\ Department of Biology, University of Michigan, Ann Arbor, MI 48109
}

\begin{abstract}
Heiser (1949) hypothesized that a weedy race of Helianthus bolanderi had originated by the introgression of genes from $H$. annuus into a serpentine race of $H$. bolanderi. Although Heiser's investigation of these species is frequently cited as one of the best examples of introgression in plants, definitive evidence of gene exchange is lacking (Heiser, 1973). To determine whether the weedy race of $H$. bolanderi actually originated via introgression, we analyzed allozyme, chloroplast-DNA (cpDNA), and nuclear-ribosomal-DNA (rDNA) variation.

Evidence from enzyme electrophoresis did not support the proposed introgressive origin of weedy $H$. bolanderi. We detected a total of 37 low-frequency alleles distinguishing the serpentine race of $H$. bolanderi from $H$. annuus. Weedy $H$. bolanderi possessed only four of the 37 marker alleles. Further analysis demonstrated that serpentine $H$. bolanderi combined seven of the 35 alleles distinguishing $H$. annuus from weedy $H$. bolanderi, indicating that serpentine $H$. bolanderi shares three more marker alleles with $H$. annuus than does weedy $H$. bolanderi. These results are similar to expectations for race divergence from a single common ancestor and suggest that, if introgression occurred, the majority of marker alleles were rapidly lost following the initial hybridization event.

Even more compelling evidence opposing Heiser's (1949) hypothesis, however, was from restriction-fragment analysis of cpDNA and nuclear rDNA. We detected a total of $17 \mathrm{cpDNA}$ and five rDNA restriction-site mutations among the 19 populations examined. No parallel or back mutations were observed in phylogenetic trees constructed using either cpDNA or rDNA mutations, and both phylogenies were completely congruent regarding the alignment of all three taxa. In addition, the weedy race of $H$. bolanderi possessed a unique cpDNA, which was outside the range of variation observed among populations of either of the presumed parental species. Mean sequence divergences between the cpDNAs of weedy $H$. bolanderi and those of serpentine $H$. bolanderi and $H$. annuus were $0.30 \%$ and $0.35 \%$, respectively. These estimates are comparable to sequencedivergence values observed between closely related species in other plant groups. Given the lack of parallel or convergent mutations in the cpDNA and rDNA phylogenetic trees, the complete congruence of these trees with flavonoid- and allozyme-variation patterns, and the presence of a unique and divergent chloroplast genome in the weedy race of $H$. bolanderi, we suggest that the weedy race of $H$. bolanderi was not derived recently through introgression, as hypothesized, but is relatively ancient in origin.
\end{abstract}

Received June 9, 1987. Accepted October 27, 1987

For the past 50 years, interspecific gene flow via hybridization and subsequent introgression has been implicated as one of the primary factors bringing about evolutionary change in many plant groups (Anderson, 1949; Stebbins, 1959, 1969; Grant, 1981). However, the frequency of occurrence and importance of introgression in the evolution of plants is unknown. Although the occurrence of backcrossed individuals in hybrid swarms is well documented (e.g., Heiser, 1949; Alston and Turner, 1963, Levin, 1975; Soltis and Soltis, 1986), the

\footnotetext{
' Present address: Rancho Santa Ana Botanic Garden, 1500 N. College, Claremont, CA 91711.
}

permanent addition of genes from one species into another, resulting in the creation and establishment of a new type, has rarely been demonstrated (Heiser, 1973). Nevertheless, numerous studies have implicated introgression in the origin and establishment of new races, varieties, subspecies, and species (e.g., Heiser, 1949, $1951 b$; Grant, 1950; Levin, 1963; Ornduff, 1967; Bloom, 1976; Davis, 1985). Although introgression may have occurred in these examples, they are based primarily on morphological data and historical inference, making conclusive documentation of introgression difficult. Other equally plausible hypotheses are convergent evolution, retention of ancestral characters, and phenotypic 
plasticity. However, the use of precise genetic markers provided by allozyme variation and restriction-site mutations in specific DNA sequences may resolve ambiguous questions of introgression.

The annual species of Helianthus (sunflowers) are particularly favorable for studying introgression (Stebbins and Daly, 1961; Heiser et al., 1969; Levin, 1975). They are widespread, self-incompatible, and weedy, often colonizing disturbed habitats. Heiser $(1947,1949,1951 a, 1951 b, 1954,1961)$ has shown that hybridization occurs frequently and that hybrids, although nearly sterile, can produce some offspring by backcrossing with the parental species. Heiser (1965) suggested that ecological amplitude and genetic variation in some of these species has been increased by this process. Finally, this group has been the subject of extensive cytological and morphological studies (Heiser, 1947, $1949,1951 a, 1951 b, 1954,1961$ ), and members of this group are often cited as outstanding examples of introgression.

The most frequently cited example of introgression in Helianthus, indeed one of the classic cases of introgression in plants, involves the two annual sunflowers of California, Helianthus annuus and $H$. bolanderi (Heiser, 1949). Helianthus annuus is a common roadside weed in California, occurring frequently in the central valley and in southern California. Helianthus annuus was already in the state when the first botanical collections were made and was used by the native Americans for various purposes (Heiser, 1949). Since it does not now occur in natural sites in California, it was very likely introduced quite recently by native Americans (Heiser, 1949; Stebbins and Daly, 1961). Helianthus bolanderi, in contrast, is native to California and was shown by Heiser (1949) to consist of two races. One of these races is restricted to the foothill regions of California and grows chiefly on serpentine-derived soils. This race is referred to as the serpentine race of $H$. bolanderi (Heiser, 1949). The other race is weedy and invades fields, ditches, and roadsides in the central valley of California; it is referred to as the weedy race of $H$. bolanderi (Heiser, 1949). The weedy race of $H$. bolanderi is sympatric with $H$. annuus in the central valley, and the two taxa form exten- sive hybrid swarms in areas of contact. Using morphological and cytological data, Heiser (1949) hypothesized that the weedy race of $H$. bolanderi developed in California through introgression of genes from the recently introduced $H$. annuus into the serpentine race of $H$. bolanderi. Although $H$. annuus and $H$. bolanderi do hybridize, and although the weedy race of $H$. bolanderi approaches $H$. annuus in a number of morphological characters, no evidence of gene exchange away from hybrid swarms has been documented. In fact, even Heiser (1973) considered his earlier morphological findings to be less than definitive and envisioned that new biochemical and genetic tools might help solve ambiguous questions of introgression.

Although allozyme variation has been used successfully to investigate introgression in animal species (e.g., Selander et al., 1969; Hunt and Selander, 1973; Avise and Smith, 1974; Avise and Saunders, 1984), the use of electrophoretic markers to study introgression in plants has been limited (Levin, 1975; Bell and Lester, 1978; Soltis and Soltis, 1986; Doebley et al., 1984; Soltis, 1985).

Comparison of cytoplasmic and nuclear genetic markers has produced perhaps the most suggestive evidence for introgression in nature, in both plants and animals. Palmer et al. (1983) demonstrated a discrepancy between biparental nuclear and maternalcpDNA phylogenies in Brassica and suggested the occurrence of introgression. Similarly, comparison of karyotypes and cpDNAs in Pisum (Palmer et al., 1985) suggested one possible instance in which cytoplasms may have been exchanged between related species. Studies of mitochondrial-DNA variation in deer (Carr et al., 1986), Drosophila (Powell 1983; Solignac and Monnerot, 1986), mice (Ferris et al., 1983), sunfish (Avise and Saunders, 1984), tree frogs (Lamb and Avise, 1986), trout (Gyllensten et al., 1985), and water frogs (Spolsky and Uzzell, 1984) have also uncovered possible cases of introgression.

Here we examine allozyme, chloroplastDNA, and nuclear-ribosomal-DNA variation among populations of $H$. annuus and $H$. bolanderi. As part of an exhaustive examination of introgression in these taxa 
(Rieseberg, 1987), some of the populations employed in this study have also been examined using flavonoid chemistry and morphology. Two specific questions are addressed in this study: 1) are allozyme, cpDNA, and rDNA data consistent with the hypothesized origin of the weedy race of $H$. bolanderi through introgression? 2) are DNA restriction-site data consistent with evidence from flavonoids and allozymes?

\section{Materials AND Methods}

Plants. - Achenes for isozyme studies were gathered from 43 populations throughout North America, including seven populations of the serpentine race of $H$. bolanderi, four populations of the weedy race of $H$. bolanderi, and 32 populations of $H$. annuus. Achenes were collected from mature heads of 30-100 individuals per population, pooled, and used for enzyme electrophoresis. A list of populations and localities is given in Rieseberg (1987).

For cpDNA and rDNA variation, five populations of the serpentine race of $H$. bolanderi (S1-S5), four populations of the weedy race of $H$. bolanderi (W1-W4), nine populations of $H$. annuus (A1-A9), and a hybrid swarm involving $H$. annuus and both races of $H$. bolanderi $(\mathrm{H})$ were examined (see Rieseberg [1987] for locality data). In addition, one population of $H$. maxmiliani (M) was used as an outgroup to polarize the direction of restriction-site mutations. Because relationships within Helianthus section Helianthus are unclear (Schilling and Heiser, 1981; Chandler et al., 1986), the outgroup was chosen from the most closely related section in Helianthus, section $\mathrm{Di}$ varicatii (Heiser et al., 1969). We sampled 1-4 individuals per population for both cpDNA and rDNA variation, with the exception of the hybrid population, from which 30 individuals were analyzed for cpDNA variation only.

Enzyme Electrophoresis. - Sample preparation, electrophoresis, and staining of enzymes followed the general methodology of Soltis et al. (1983). The following enzymes (loci in parentheses) were examined: alcohol dehydrogenase $(A d h-1,2)$, aldolase (Ald$1,2,3), \beta$-galactosidase $(\beta G a l)$, fructose-1,6diphosphatase $(F d p-1,2)$, glutamate dehydrogenase $(G d h)$, isocitrate dehydrogenase
$(I d h-1,2)$, leucine aminopeptidase (Lap-1,2), malate dehydrogenase $(M d h-2,3)$, malic enzyme $(M e-1)$, phosphoglucoisomerase (Pgi$1,2)$, phosphoglucomutase $(P g m-1,3)$, 6-phosphogluconate dehydrogenase $(\mathrm{Pgd}-3)$, and triosephosphate isomerase (Tpi-1,2,3). All enzymes were resolved on $12.5 \%$ starch gels. Gel and electrode buffer systems used are given in Rieseberg et al. (1988).

DNA Isolation. - High-molecular-weight total DNA (nuclear, chloroplast, and mitochondrial) was isolated for analysis of rDNA variation using the method of Doyle and Doyle (1987). Chloroplast DNAs from pooled single-population samples of $H$. annuus (A1) and serpentine $H$. bolanderi (S1) and from three individuals from the hybrid swarm $(\mathrm{H})$ were prepared from fresh leaves following the protocol of Palmer (1982). For the remaining populations (S2-S5, W1-W4, $\mathrm{A} 2-\mathrm{A} 9, \mathrm{H}, \mathrm{M}$ ), as well as for individual samples from populations $A 1$ and $S 1$, chloroplasts were isolated from fresh leaves of individual plants using the sucrose-gradient procedure described in Palmer (1982, 1986). Chloroplast DNAs were then isolated from the purified chloroplast preparations following the method of Doyle and Doyle (1987), starting with the addition of hot extraction buffer to the cpDNA pellet.

Restriction-Site Comparisons. - Restriction-endonuclease digestions, agarose-gel electrophoresis, bidirectional transfer of DNA from agarose gels to nitrocellulose filters, preparation of ${ }^{32} \mathrm{P}$-labeled probes, and filter hybridizations were conducted following the methods of Palmer (1986). Preparation and detection of biotin-labeled probes followed the instructions of the manufacturer (Bethesda Research Laboratories).

Thirty-six restriction endonucleases were used to examine cpDNA variation in $\mathrm{He}$ lianthus, including 30 endonucleases that recognize six-bp (base pair) sequences, four endonucleases that recognize five-bp pair sequences, and two endonucleases that recognize four-bp sequences. Restriction-site mutations were detected by visualizing agarose gels stained with ethidium bromide under ultraviolet light. Restriction-site mutations were then characterized by hybridizing with clones containing $S a c$ I fragments from lettuce (Jansen and Palmer, 1987a, 1987b). The 15 clones utilized, representing $95 \%$ of 
the chloroplast genome, were divided into four groups, and each group of clones was used as a single probe. Given the similarity of Helianthus cpDNAs $(<1 \%$ sequence divergence), it was not necessary to map restriction-site mutations to interpret the observed fragment differences.

To analyze rDNA variation in Helianthus, 22 restriction endonucleases were used, including 17 endonucleases that recognize six-bp sequences, and five endonucleases that recognize five-bp sequences. Two probes were used to detect homologous segments of Helianthus rDNA: 1) pHA-1, a plasmid containing a single $18 \mathrm{~S}-25 \mathrm{~S}$ rDNA repeat from Pisum (Jorgensen et al., 1987) and 2) pGMr-1, a plasmid containing a single 18S-25S rDNA repeat from Glycine max (Doyle and Beachy, 1985). Ribosomal DNAs within and among populations of Helianthus annuus and $H$. bolanderi were very similar, and fragment differences between mutated DNAs were easily interpreted without detailed mapping of restriction sites.

Data Analysis. - Genetic-identity values were computed following Nei (1972) for all pairwise population comparisons using the BIOSYS-1 program of Swofford and Selander (1981). Chloroplast-DNA sequence-divergence values were computed using the equations of Brown et al. (1979). Ribosomal-DNA sequence-divergence values were not computed, because it is likely that additional site mutations are present in the nontranscribed intergenic spacer but were not detected because of nonhomology to the probes used. Thus, these values could bias estimates of sequence divergence. Phylogenetic analyses of cpDNA and rDNA data were conducted using the computer program "Phylogenetic Analysis Using Parsimony" (PAUP, version 2.3) developed by Swofford (1983). For each data set, cladistic analysis was performed using a designated outgroup.

\section{RESULTS}

Allozyme Similarity and the Distribution of Taxon-Specific Alleles.-Genetic-identity values within and among the three taxa under investigation are extremely high. Mean genetic identities within each taxon range from 0.97 for $H$. annuus to 0.98 for each race of $H$. bolanderi. Mean identities among the three taxa range from 0.96 between either race of $H$. bolanderi and $H$. annuus to 0.98 between serpentine $H$. bolanderi and weedy $H$. bolanderi. The mean genetic identity for comparisons of all populations of $H$. annuus and $H$. bolanderi examined is 0.97 .

Although $H$. annuus and the two races of $H$. bolanderi are very similar at genes coding for enzymes, each taxon possesses unique alleles, as well as alleles detected in only one of the other two taxa. The distribution of these "marker alleles" was used to examine the hypothesized origin of the weedy race of $H$. bolanderi through introgression. A total of 37 low-frequency alleles distinguish the serpentine race of $H$. bolanderi from $H$. annuus. Weedy $H$. bolanderi combined only four of the 37 alleles exclusive to the putative parental species. Serpentine $H$. bolanderi, however, combined seven of the 35 alleles differentiating weedy $H$. bolanderi from $H$. annuus, and $H$. annuus combined seven of the 16 alleles differentiating the two races of $H$. bolanderi.

Chloroplast-DNA Variation. - The chloroplast genome of Helianthus is similar in size and organization to the vast majority of angiosperms examined (Palmer, 1985). The only major difference is a $22-\mathrm{kb}$ inversion in the large single-copy region of most Compositae species, including species of Helianthus (Jansen and Palmer, 1987b). Our size estimate of $151 \mathrm{~kb}$ for the Helianthus chloroplast genome is very similar to size values obtained in previous studies of Compositae species (reviewed in Jansen and Palmer [1987a]).

Variation among cpDNAs of Helianthus was analyzed by digesting each cpDNA with 36 restriction endonucleases and comparing 507 restriction sites (approximately 2,927 nucleotide bases). Chloroplast-DNA mutations encountered in $H$. annuus and $H$. bolanderi are summarized in Table 1. All 17 fragment-pattern differences detected were diagnosed as restriction-site mutations (point mutations). No length mutations or inversions were detected. Polarity of restriction-site mutations is given relative to $H$. maxmiliani.

Four restriction-site mutations differentiate all populations of $H$. bolanderi (S1-S5 and W1-W4) from all populations of $H$. 
TABlE 1. Chloroplast-DNA restriction-fragment changes in Helianthus. Only well resolved fragments were scored. Therefore, fragments below $1 \mathrm{~kb}$ in size generally were not scored. Each restriction-site change is inferred to result from a single point mutation within a restriction site. The evolutionary direction of restriction-site mutations is given relative to $H$. maxmiliani. No point mutations were observed with $B c l$ I ( 14 fragments), $B g l$ I (10 fragments), BstE II ( 9 fragments), Bst N I (1 3 fragments), BstX I (14 fragments), Cfo I (16 fragments), EcoR V (20 fragments), Hae II (13 fragments), Hpa I (13 fragments), Hpa II (11 fragments), Nco I (15 fragments), $N d e$ I (16 fragments), Nhe I (5 fragments), Nru I (15 fragments), Pst I ( 9 fragments), Pvu I ( 9 fragments), Sac II (11 fragments), Sal I (9 fragments), SnaB I (16 fragments), Ssp I (21 fragments), Tth111 I (10 fragments), or Xba I (14 fragments).

\begin{tabular}{|c|c|c|c|c|}
\hline \multirow[b]{2}{*}{ Restriction enzyme } & \multirow{2}{*}{$\begin{array}{c}\text { Number of } \\
\text { fragments scored }\end{array}$} & \multicolumn{2}{|c|}{ Changed fragments } & \multirow[b]{2}{*}{ Populations with mutated DNAs } \\
\hline & & Loss & Gains & \\
\hline Apa I & 9 & $3.8+3.8$ & 7.6 & S1-S5 \\
\hline Ava I & 22 & $3.7+7.3$ & 10.0 & S1-S5 \\
\hline$B a m \mathrm{H}$ I & 19 & 9.3 & $5.8+3.5$ & S1-S5 \\
\hline$B g l$ II & 20 & 5.5 & $5.1+0.4$ & W1-W4 \\
\hline Cla I & 22 & $3.7+0.4$ & 4.1 & W1-W4 \\
\hline \multirow[t]{2}{*}{ Dra $\mathbf{I}$} & 17 & 6.0 & $5.1+0.9$ & S1-S5 \\
\hline & & 3.0 & $2.3+0.7$ & A1-A9 \\
\hline EcoR I & 17 & 9.5 & $6.0+3.5$ & $\mathrm{~S} 1, \mathrm{~S} 5$ \\
\hline Hind III & 15 & 9.0 & $8.3+0.7$ & S1-S5, W1-W4 \\
\hline$K p n \mathrm{I}$ & 8 & $14.7+3.1$ & 17.8 & $\mathrm{~A} 1-\mathrm{A} 2, \mathrm{~A} 5-\mathrm{A} 7, \mathrm{~A} 9$ \\
\hline$N c i \mathrm{I}$ & 13 & $3.2+0.5^{*}$ & 3.7 & A8 \\
\hline Sac I & 17 & 4.6 & $3.4+1.2$ & WI-W4 \\
\hline Spe I & 15 & $21.0+4.2$ & 25.2 & S1-S5, W1-W4 \\
\hline \multirow[t]{2}{*}{ Stu I } & 11 & 5.5 & $3.7+1.8$ & $\mathrm{~S} 1-\mathrm{S} 5$ \\
\hline & & 16.3 & $15.4+0.9$ & $\mathrm{~A} 1-\mathrm{A} 9$ \\
\hline \multirow[t]{2}{*}{$X m n \mathbf{I}$} & 19 & 3.7 & $3.0+0.7$ & Al-A 7, A9 \\
\hline & & $1.7+0.4^{*}$ & 2.1 & A4 \\
\hline
\end{tabular}

* Fragment too small to be visualized.

annuus (A1-A9). Populations of $H$. bolanderi share derived Hind III and Spe I restriction sites, whereas all populations of $H$. annuus share derived Dra I and Stu I restriction sites (Table 1). The serpentine race of $H$. bolanderi $(\mathrm{S} 1-\mathrm{S} 5)$ is characterized by five unique restriction-site mutations ( $A p a$ I, Ava I, BamH I, Dra I, and Stu I; Table 1), and populations of weedy $H$. bolanderi (W1-W4) can be differentiated from all other populations by three restriction-site mutations (Bgl II, Cla I, and Sac I; Table 1).

Intraspecific cpDNA variation was observed in both $H$. bolanderi and $H$. annuus. The two races of $H$. bolanderi differ by eight or nine restriction-site mutations, depending on the populations compared (Table 1). However, no mutations were observed among populations of weedy $H$. bolanderi, and only a single $E c o$ R I restriction-site mutation was observed among populations of serpentine $H$. bolanderi. In $H$. annuus, three restriction-site mutations serve to differentiate populations.

Examination of the cpDNAs of 30 indi- viduals from a hybrid swarm demonstrated the presence of three different cpDNAs in the population. Twenty-four of the 30 individuals assayed possessed a chloroplast genome identical to that of populations W1W4, five plants possessed a chloroplast genome identical to that of population A3, and one plant had a chloroplast genome identical to that of populations S2-S4. No novel cpDNAs were observed in the hybrid swarm.

Sequence-divergence values (Table 2) among Helianthus cpDNAs were calculated using the 30 six-bp pair restriction enzymes. Sequence-divergence values among populations of weedy $H$. bolanderi, serpentine $H$. bolanderi, and $H$. annuus were $0.00 \%$, $0.02 \%$, and $0.04 \%$, respectively. Mean cpDNA sequence divergence among these three taxa ranged from $0.30 \%$ between the two races of $H$. bolanderi to $0.40 \%$ between serpentine $H$. bolanderi and $H$. annuus. The average sequence divergence was $0.35 \%$.

A phylogenetic tree based on the 17 cpDNA restriction-site mutations listed in 


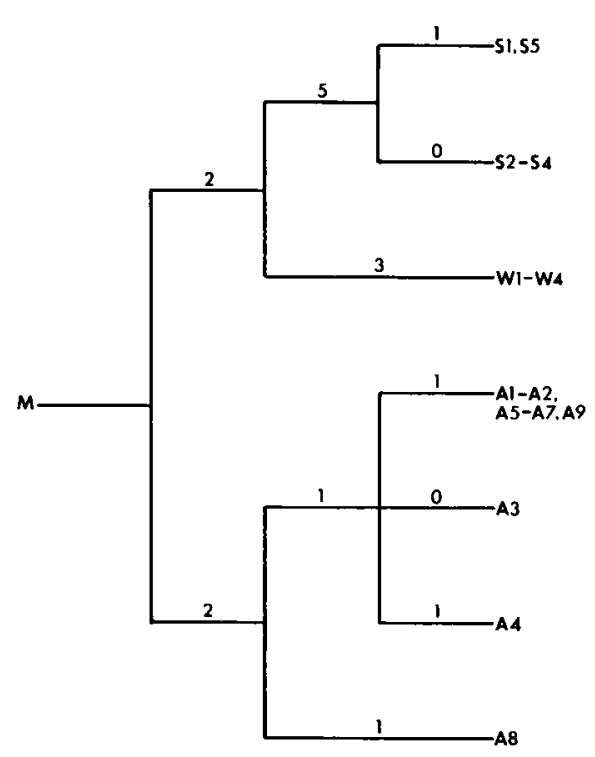

Fig. 1. Phylogenetic tree of 18 Helianthus populations based on 17 restriction-site mutations. The tree is rooted relative to $H$. maxmiliani restriction sites. Population descriptions are given at the ends of the branches, and the number of mutations is given above each branch.

Table 1 is given in Figure 1. The PAUP program found a single most parsimonious tree, which required only 17 mutations to account for the observed distribution of the seven cpDNA phenotypes. Thus, there is no need to postulate any convergent restriction-site mutations. However, populations [A1-A2, A5-A7, A9] form an unresolved trichotomy with populations A3 and A4 (Fig. 1). It is likely that the observed trichotomy simply reflects a lack of potentially resolving characters.

Ribosomal-DNA Variation. - Nuclear ri-
bosomal-RNA genes in higher plants are organized as arrays of tandemly repeated genes (reviewed in Appels and Honeycutt [1986]). Ribosomal RNA is transcribed as a single transcript and subsequently processed into $18 \mathrm{~S}, 5.8 \mathrm{~S}$, and $25 \mathrm{~S}$ rRNAs. Each repeat unit contains both a ribosomal-RNA transcription unit and an intergenic spacer (IGS) sequence that separates the transcription units of adjacent repeats. The rRNA coding sequence is generally highly conserved, whereas the spacer regions are often highly variable in both sequence and length within and among individuals, populations, and species (e.g., Doyle et al., 1984; Polans et al., 1986; Sytsma and Schaal, 1985b; Saghai-Maroof et al., 1984; Appels and Dvorak, 1982; Appels et al., 1980). The IGS sequence usually contains a region of small tandem subrepeats, and length heterogeneity generally results from changes in copy number of the subrepeats.

No repeat-length heterogeneity was observed within individuals, populations, or species of Helianthus. However, H. maxmiliani possessed a repeat of $10.5 \mathrm{~kb}$, whereas $H$. annuus and the two races of $H$. bolanderi possessed a $9.9-\mathrm{kb}$ repeat. The complete lack of rDNA repeat-length variation within Helianthus species contrasts sharply with the extensive variation observed within numerous other species (e.g., Saghai-Maroof et al., 1984; Doyle et al., 1984; Appels and Dvorak, 1982; Polans et al., 1986). This rDNA homogeneity greatly simplified intra- and interspecific rDNA comparisons in Helianthus.

However, in contrast to the lack of repeatlength heterogeneity within single individ-

TABLE 2. Sequence differences among Helianthus chloroplast DNAs. The number of restriction-site mutations between any two cpDNAs is given in the upper right-hand section of the matrix; values given in the lower lefthand section are the percentages of sequence divergence (Brown et al., 1979). Divergence estimates are based on 30 six-bp restriction enzymes. We compared a total of 2,514 bp (419 six-bp restriction sites; Table 1).

\begin{tabular}{|c|c|c|c|c|c|c|c|}
\hline \multirow[b]{2}{*}{ Populations } & \multicolumn{7}{|c|}{ Populations } \\
\hline & {$[\mathbf{S} 1, \mathbf{S} 5]$} & [S2-S4] & [W1-W4] & $\begin{array}{c}{[\mathrm{A} 1-\mathrm{A} 2} \\
\mathrm{A} 5-\mathrm{A} 7, \mathrm{~A} 9]\end{array}$ & [A3] & [A4] & [A8] \\
\hline$[\mathrm{S} 1, \mathrm{~S} 5]$ & - & 1 & 8 & 11 & 10 & 11 & 9 \\
\hline [S2-S4] & 0.04 & - & 7 & 10 & 9 & 10 & 8 \\
\hline [W1-W4] & 0.32 & 0.28 & - & 9 & 8 & 9 & 7 \\
\hline$[\mathrm{A} 1-\mathrm{A} 2, \mathrm{~A} 5-\mathrm{A} 7, \mathrm{~A} 9]$ & 0.44 & 0.40 & 0.36 & - & 1 & 2 & 2 \\
\hline [A3] & 0.40 & 0.36 & 0.32 & 0.04 & - & 1 & 1 \\
\hline [A4] & 0.44 & 0.40 & 0.36 & 0.08 & 0.04 & - & 2 \\
\hline [A8] & 0.36 & 0.32 & 0.28 & 0.08 & 0.04 & 0.08 & - \\
\hline
\end{tabular}


uals, a limited amount of restriction-site polymorphism was observed among repeat units within single individuals in Helianthus. These restriction-site polymorphisms may be due to nucleotide substitutions, differential methylation, and/or partial digests and were observed among repeat units using $B a m \mathrm{H}$ I and EcoR I which recognize sequences prone to methylation (Gerlach and Bedbrook, 1979; Siegel and Kolacz, 1983). That rDNA restriction sites are polymorphic within single plants may simply reflect that these species are of ancient tetraploid $(N=17)$ origin (Jackson and Murray, 1983). Isozyme number also reflects the polyploid status of these species (Rieseberg and Soltis, unpubl.). Additional isozymes per enzyme, relative to the number of isozymes characteristic of diploid seed plants (Gottlieb, 1982), were observed for aldolase, fructose-1,6-diphosphatase, malic enzyme, phosphoglucomutase, 6-phosphogluconate dehydrogenase, and triosephosphate isomerase.

Although no rDNA repeat-length heterogeneity was observed, ribosomal-DNA restriction-site variation was detected among populations of $H$. annuus and $H$. bolanderi (Table 3). We observed a total of five restriction-site mutations. Polarity of restriction-site mutations is given relative to $H$. maxmiliani. Three restriction-site mutations differentiate all populations of $H$. bolanderi (S1-S5 and W1-W4) from all populations of $H$. annuus (A1-A9). Populations of $H$. bolanderi share derived Hinc II restriction sites, whereas populations of $H$.

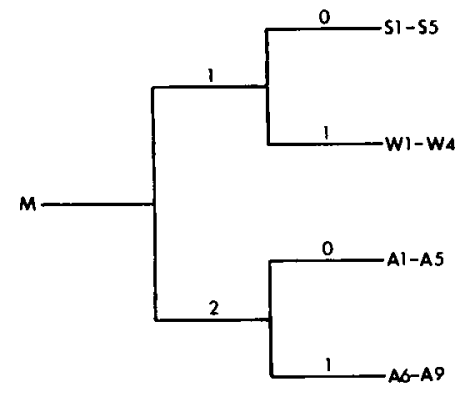

FIG. 2. Phylogenetic tree of 18 Helianthus populations based on five rDNA restriction-site mutations. The tree is rooted relative to $H$. maxmiliani restriction sites. Population designations are given at the ends of branches, and the numbers of mutations are given above the branches.

annuus share derived BamH I, and Nco I restriction sites (Table 3 ). Little intraspecific rDNA variation was observed in $H$. annuus and $H$. bolanderi (Table 3). A Spe I restriction-site mutation differentiates the weedy and serpentine races of $H$. bolanderi, and a Hinc II mutation divides $H$. annuus into two groups.

A phylogeny based on five rDNA restriction-site mutations is given in Figure 2. The PAUP program found a single most parsimonious tree that required only five mutations to account for the observed distribution of the four rDNA phenotypes. Once again, there is no need to postulate any convergent restriction-site mutations.

Chloroplast- and Ribosomal-DNA Phylogeny. - A phylogenetic tree was constructed from pooled rDNA and cpDNA data (Fig. 3). A single most parsimonious tree was

TABLE 3. Restriction-fragment changes of nuclear ribosomal DNA in Helianthus. Each restriction-site change is inferred to result from a single point mutation within a restriction site. The evolutionary direction of restrictionsite mutations is given relative to $H$. maxmiliani. No point mutations were observed with $B a n$ I ( 3 fragments), $B s t$ E II (1 fragment), Dra I (2 fragments), EcoR I (2 fragments), EcoR V (1 fragment), Hind III (1 fragment), Nde I (1 fragment), Nhe I (1 fragment), Sac I (3 fragments), Ssp I (1 fragment), Tth111 I (3 fragments), Xba I (1 fragment), or $X m n$ I (2 fragments). Bcl I, Bgl II, BstN I, $N c i$ I, and Stu I apparently recognize no sites in the rDNA repeat. At least one additional mutation has occurred at Hinc II.

\begin{tabular}{|c|c|c|c|c|}
\hline \multirow[b]{2}{*}{ Restriction enzyme } & \multirow{2}{*}{$\begin{array}{c}\text { Number of } \\
\text { fragments scored }\end{array}$} & \multicolumn{2}{|c|}{ Changed fragments } & \multirow[b]{2}{*}{ Mutated DNAs } \\
\hline & & Losses & Gains & \\
\hline BamH I & $4-5$ & $3.1+1.8$ & 4.9 & A1-A9 \\
\hline \multirow[t]{2}{*}{ Hinc II } & 3 & $4.5+0.2^{*}$ & 4.7 & A6-A9 \\
\hline & & $4.5+0.4^{*}$ & 4.9 & S1-S5, W1-W4 \\
\hline Nco I & $2-3$ & 9.0 & $4.8+4.2$ & A $1-A 9$ \\
\hline Spe I & $0-1$ & 9.9 & ** & W 1-W4 \\
\hline
\end{tabular}

* Fragment not detected by probe; probably occurs in the highly diverged nontranscribed spacer region.

** No cleavage sites. 


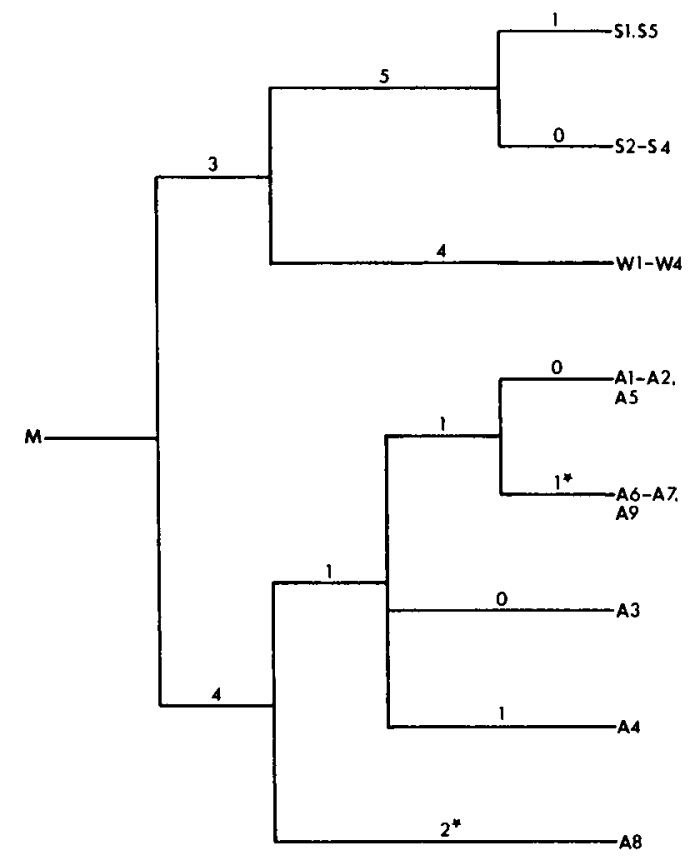

Fig. 3. Phylogenetic tree of 18 Helianthus populations using pooled $\mathrm{cpDNA}$ and rDNA data. The tree is rooted relative to $H$. maxmiliani restriction sites. Population designations are given at the ends of branches, and the numbers of mutations are given above the branches. Convergent mutations are designated by stars.

found for the eight DNA phenotypes. This rooted tree (Fig. 3) required only one additional mutation ( 24 steps) to account for the observed data. The consistency index was 0.96 , and the rate of convergence was $4.2 \%$. The single convergence occurred among populations of $H$. annuus and was observed only after combining the two data sets. The apparent convergent mutation occurred in population A8 and in populations [A6-A7, A9]. Population A8 has a very distinct chloroplast genome relative to the other three populations, but all four populations have an identical rDNA phenotype. Two hypotheses may account for the apparent convergence: 1) parallel restrictionsite mutations occurred in two lineages of $H$. annuus; or 2) exchange of biparentally inherited rDNA genes occurred among populations of $H$. annuus in the absence of cytoplasmic gene flow. A trichotomy was observed among the same populations of $H$. annuus that were involved in the trichotomy associated with the cpDNA phylogenetic tree.

\section{DISCUSSION}

Allozyme Variation and Introgression.The high genetic identities observed between serpentine $H$. bolanderi, weedy $H$. bolanderi, and $H$. annuus $(I=0.97)$ indicate that, for genes encoding enzymes, little genetic differentiation among taxa has occurred. In fact, these values are more similar to genetic identities reported for conspecific plant populations of other plant groups than to values comparing other congeneric plant species (Gottlieb, 1981; Crawford, 1983).

Because of the high level of allozymic similarity, the electrophoretic data set cannot be used to test the introgression hypothesis formally. This is because only a few of the 37 low-frequency marker alleles would be expected in the interspecific $F_{1}$ hybrids (due to the rarity of these alleles). Nevertheless, the observation that serpentine $H$. bolanderi shares three more marker alleles with $H$. annuus than does weedy $H$. bolanderi certainly does not support the introgression model. Instead, these results are similar to expectations for race divergence from a single common ancestor and suggest that, if introgression occurred, the majority of marker alleles were rapidly lost following the initial hybridization event.

In contrast to the allozyme data, much greater differentiation was observed between the chloroplast and ribosomal DNAs of these species, making the latter two data sets most useful for testing the introgression hypothesis. Ribosomal-DNA variation can be used to detect hybridization and introgression, because rDNA should be additively combined in hybrids or introgressants. Chloroplast DNA can be particularly useful for studying introgression, because cpDNAs do not recombine. A cpDNA from one of two putative parents should be present in hybrids or introgressants (not a cpDNA unlike either of them).

Chloroplast-DNA Sequence Divergence. - Mean sequence divergence ranged from 0.3 to $0.4 \%$ among the three Helianthus taxa analyzed. These estimates are similar to values obtained for closely related species of Lycopersicon ( $0-0.7 \%$; Palmer and Zamir, 1982), Pennisetum (0.4\%; Clegg et al., 1984), Pisum (0.1-0.8\%; Palmer et al., 1985), and Lisianthius (0-0.3\%; Sytsma and Schaal, $1985 b$ ), but generally lower than es- 
timates obtained in Brassica (0.3-2.6\%; Palmer et al., 1983), Clarkia (0.2-1.6\%; Sytsma and Gottlieb, 1986), and Linum (0$6 \%$; Coates and Cullis, 1987). However, mean sequence divergence between the two races of $H$. bolanderi is extremely high given the proposed recent divergence of these lineages (Heiser [1949] suggests that the weedy race of $H$. bolanderi may have been derived through introgression as recently as during the past several hundred years). In fact, this much cpDNA sequence divergence has never been observed within a plant species before. Zurawski et al. (1984) estimated that the synonymous rate of sequence change of the cpDNA-encoded $r b c L$ gene among grasses is $1 \times 10^{-9}$ nucleotide substitutions per year. If $H$. bolanderi cpDNA is evolving at a similar rate (however unrealistic this assumption may be), estimated time of divergence between the weedy and serpentine race is approximately $3,000,000$ years. Thus, cpDNA-divergence estimates suggest that the two races of $H$. bolanderi may be far more ancient than was previously hypothesized, and, on the basis of cpDNA data alone, these races could be viewed as separate species. Alternatively, cpDNA divergence may have occurred rapidly in these two lineages. If we postulate that the two lineages diverged approximately 1,000 years ago, a 3,000-fold increase in evolutionary rates (relative to the estimates of Zurawski et al., [1984]) would have to be postulated to account for the observed cpDNA divergence in $H$. bolanderi. It is possible that interaction of chloroplast and nuclear genes from different parents in later generations of interspecific hybrids might result in unstable cpDNAs, increasing the rate of cpDNA evolution in Helianthus. However, the complete absence of novel cpDNA phenotypes in 30 individuals from a 45-yearold hybrid swarm containing $F_{1}$ and latergeneration plants (Stebbins and Daly, 1961) suggests that interspecific hybridization and backcrossing do not produce rapid cpDNA changes in Helianthus.

Evidence from cpDNA and evidence from isozymes provide conflicting estimates of genetic divergence between the two races of $H$. bolanderi and between $H$. bolanderi and $H$. annuus. The Helianthus populations compared were very similar at genes encoding enzymes $(\bar{I}=0.97)$, but had diver- gent cpDNAs $(0.3-0.4 \%$ sequence divergence). This result is in explicit contrast to the situation in Lisianthius (Sytsma and Schaal, 1985a, 1985b), where much lower levels of cpDNA variation $(0-0.3 \%)$ were observed relative to isozyme variation $(\bar{I}=$ 0.62 ). The high degree of isozyme similarity in Helianthus could be attributed to selective control of isozymes (or linked genes) or to gene flow and recombination. Gene flow, however, is an unlikely mechanism for maintaining homogeneity between populations of $H$. annuus and $H$. bolanderi, given their lengthy geographic isolation.

Phylogenetic Relationships. - Analysis of biparentally inherited rDNA and maternally inherited cpDNA (Tilney-Bassett, 1978) provides a phylogenetic history of populations of $H$. annuus and $H$. bolanderi. In phylogenetic trees derived from both cpDNA and rDNA data, the alignment of the two races of $H$. bolanderi and $H$. annuus did not change (Figs. 1-3). The two races of $H$. bolanderi form a monophyletic lineage supported by three synapomorphies (two cpDNA and one rDNA mutations). Likewise, all populations of $H$. annuus form a monophyletic lineage supported by four synapomorphies (two cpDNA and two rDNA mutations).

Phylogenetic analysis of cpDNA and rDNA restriction-site variation also resolved populations within the serpentine race of $H$. bolanderi and within $H$. annuus (Fig. 3). Two DNA phenotypes were observed in serpentine $H$. bolanderi. Populations $\mathrm{S} 1$ and $\mathrm{S} 5$ correspond to the extreme "exilis" form of serpentine $H$. bolanderi (Oliveri and Jain, 1977), whereas populations S2-S4 are the "foothills" form of serpentine $H$. bolanderi. In contrast, DNA variation among populations of $H$. annuus does not correlate well with geographic distribution or morphological variation. The poor correlation probably results from repeated episodes of long-distance dispersal by man (Heiser, 1949, 1954). However, some insight into the evolutionary history of this species can be gleaned. First, it is clear that population $\mathrm{A} 8$, which represents $H$. annuus ssp. texanus (Heiser, 1954), was derived early in the evolution of $H$. annuus. The remaining eight populations correspond to $H$. annuus ssp. lenticularis. Heiser $(1949,1954)$ suggests that ssp. lenticularis 
has been introduced into California on numerous occasions. This contention is clearly supported by the fact that all three California populations analyzed have different DNA phenotypes. Finally, the three populations from the Midwest have identical DNA phenotypes (A6-A7 and A9). Given the abundance of $H$. annuus in the Midwest, these populations may possess the most common DNA phenotype in $H$. annuus.

Origin of the Weedy Race of $H$. bolanderi.-Discrepancies between nuclear and cytoplasmic phylogenies have provided evidence suggesting the occurrence of introgression in Brassica (Palmer et al., 1983), Pisum (Palmer et al., 1985), Drosophila (Powell, 1983; Solignac and Monnerot, 1986), and Mus (Ferris et al., 1983). However, with the exception of a single convergent mutation within $H$. annuus, no discrepancies were observed between cytoplasmic and nuclear phylogenetic trees in Helianthus. A hybridization or introgression event might result in reticulate patterns of evolution in a phylogenetic tree constructed using biparentally inherited characters. However, no convergent or back mutations were observed in the Helianthus phylogenetic tree constructed using rDNA mutations, nor were any additive rDNA phenotypes observed in weedy $H$. bolanderi plants, although additive rDNA profiles were observed for the majority of individuals from the hybrid swarm. Finally, if introgression were recent (as proposed for the origin of the weedy race of $H$. bolanderi), the presumed introgressant type would be expected to possess the chloroplast genome of one of the two parent species. Therefore, the presence of a unique and highly diverged chloroplast genome in the weedy race of $H$. bolanderi, when compared to cpDNAs of serpentine $H$. bolanderi and $H$. annuus, suggests that this race was not derived through introgression during the past several hundred years, as hypothesized, but is probably relatively ancient in origin.

Evidence from cpDNA and rDNA variation is consistent with foliar and floral flavonoid variation (Rieseberg and Soltis, 1988) and with allozymic variation. Although more than 60 taxon-specific markers were utilized in these studies, no evidence of interspecific gene transfer was observed.
Given the complete agreement of these four data sets, we conclude that the weedy race of $H$. bolanderi did not originate through introgression of genes from $H$. annuus.

An alternative hypothesis to account for race formation in $H$. bolanderi may be isolation via discontinuities in geology and edaphics. The adaptation of certain populations of $H$. bolanderi to serpentine soils and subsequent reduction in gene flow may have initiated race formation in this species. We have no evidence in support of this hypothesis, other than the observed distribution of the weedy and serpentine races in California.

In conclusion, primary reliance on morphological data for studies of introgression may be misleading. As we have demonstrated in this study, precise genetic markers, representing both nuclear and cytoplasmic genomes, are the most appropriate tools for the study of introgression. Given the presumed importance of introgression in plant evolution and the ready availability of appropriate methodologies, unambiguous documentation of introgression (or, conversely, the documentation of the absence of introgression) in other plants is imperative. Only with the accumulation of data from other plant groups will we be able to assess accurately the role of introgression in the evolution of vascular plants.

\section{ACKNOWLEDGMENTS}

Research was supported by NSF Grant BSR 8315088 to D.E.S., NSF Grant BSR 8415934 to J.D.P., a NSF Dissertation Improvement Grant to L.H.R. and D.E.S., a Sigma Xi Award to L.H.R., and a Washington State University Travel Grant to L.H.R. We thank the following individuals D. Crawford, J. Doyle, A. J. Gilmartin, L. Gottlieb, R. Jansen, P. Soltis, and J. Thompson for laboratory assistance, helpful discussions, and critical reviews of the manuscript.

\section{Literature Cited}

Alston, R. E., AND B. L. TURNer. 1963. Natural hybridization among four species of Baptisia (Leguminosae). Amer. J. Bot. 50:159-173.

ANDERSON, E. 1949. Introgressive Hybridization. Wiley, N.Y.

Appels, R., AND J. DvoraK. 1982. The wheat ribosomal spacer region. Its structure and variation in 
populations and among species. Theoret. Appl. Genet. 63:337-348.

Appels, R., W. L. Gerlach, E. E. Dennis, H. Swift, AND W. J. PEACOCK. 1980. Molecular and chromosomal organization of DNA sequences coding for ribosomal RNAs in cereals. Chromosoma 78: 293-311.

APPELS, R., AND R. L. HoNEYCUTt. 1986. rDNA evolution over a billion years, pp. 81-135. In S. K. Dutta (ed.), DNA Systematics. CRC Press, Boca Raton, FL.

Avise, J. C., ANd N. C. Saunders. 1984. Hybridization and introgression among species of sunfish ( $L e-$ pomis): Analysis of mitochondrial DNA and allozyme markers. Genetics 108:237-255.

Avise, J. C., AND M. H. SMith. 1974. Biochemical characters of sunfish. I. Geographic variation and subspecific intergradation in the bluegill, Lepomis macrochirus. Evolution 28:42-56.

Bell, N. B., AND L. J. Lester. 1978. Genetic and morphological detection of introgression in a clinal population of Sabatia section Campestria (Gentianaceae). Syst. Bot. 3:87-104.

BLoom, W. L. 1976. Multivariate analysis of the introgressive replacement of Clarkia nitens by Clarkia speciosa polyantha (Onagraceae). Evolution 30: $412-424$.

Brown, W. M., M. George, JR., AND A. C. Wilson. 1979. Rapid evolution of animal mitochondrial DNA. Proc. Nat. Acad. Sci. USA 76:1967-1971.

Carr, C. M., S. W. Ballinger, J. N. Derr, L. H. BLANKENSHIP, AND J. W. BICKHAM. 1986. Mitochondrial DNA analysis of hybridization between sympatric white-tailed deer and mule deer in west Texas. Proc. Nat. Acad. Sci. USA 83:9576-9580.

Chandler, J. M., C. JAN, AND B. H. Beard. 1986. Chromosomal differentiation among the annual Helianthus species. Syst. Bot. 11:353-371.

ClegG, M. T., J. R. Y. Rawson, and K. Thomas. 1984. Chloroplast DNA variation in pearl millet and related species. Genetics 106:449-461.

Coates, D., and A. C. Cullis. 1987. Chloroplast DNA variability among Linum species. Amer. J. Bot. 74:260-268.

Crawford, D. J. 1983. Phylogenetic and systematic inferences from electrophoretic studies, pp. 257287. In S. D. Tanksley and T. J. Orton (eds.), Isozymes in Plant Genetics and Breeding. Elsevier, Amsterdam, Neth.

DAvis, J. I. 1985. Introgression in Central American Phytolacca (Phytolaccaceae). Amer. J. Bot. 72:1944 1953.

Doebley, J. F., M. M. Goodman, And C. W. Stuber. 1984. Isoenzymatic variation in Zea (Gramineae). Syst. Bot. 9:203-218.

DOYLE, J. J., AND R. N. BeACHY. 1985. Ribosomal gene variation in soybean (Glycine) and its relatives. Theoret. Appl. Genet. 70:369-376.

DOYle, J. J., R. N. BeACHY, AND W. H. LeWIS. 1984. Evolution of rDNA in Claytonia polyploid complexes, pp. 321-341. In W. F. Grant (ed.), Plant Biosystematics: 40 Years Later. Academic Press, Toronto, ON, Canada.

Doyle, J. J., AND J. L. Doyle 1987. A rapid DNA isolation procedure for small amounts of fresh leaf tissue. Phytochem. Bull. 19:11-15.
Ferris, S. D., R. D. SAge, C.-M. Huang, J. T. Nielsen, U. RitTe, AND A. C. Wilson. 1983. Flow of mitochondrial DNA across a species boundary. Proc. Nat. Acad. Sci. USA 80:2290-2294.

Gerlach, W. L., AND J. R. Bedbrook. 1979. Cloning and characterization of ribosomal DNA genes from wheat and barley. Nucl. Acids Res. 7:1869-1885.

GotTlieB, L. D. 1981 . Electrophoretic evidence and plant populations. Prog. Phytochem. 7:1-46.

- 1982. Conservation and duplication of isozymes in plants. Science 216:373-380.

Grant, V. 1950. Genetic and taxonomic studies in Gila. Aliso 2:239-316. N.Y.

Gyllensten, U., R. F. Leary, F. W. Allendorf, and A. G. WILsoN. 1985. Introgression between two cutthroat trout subspecies with substantial karyotypic, nuclear and mitochondral genomic divergence. Genetics 111:905-915.

Heiser, C. B. 1947. Hybridization between the sunflower species Helianthus annuus and $H$. petiolaris. Evolution 1:249-261.

- 1949. Study in the evolution of the sunflower species Helianthus annuus and $H$. bolanderi. Univ. Calif. Publ. Bot. 23:157-196.

- 1951a. Hybridization in the annual sunflowers: Helianthus annuus $\times H$. argophyllous. Amer. Natur. 85:64-72.

- $1951 b$. Hybridization in the annual sunflowers: Helianthus annuus $\times H$. debilis var. $c u$ cumerifolius. Evolution 5:42-51.

-1954. Variation and subspeciation in the common sunflower, Helianthus annuus. Amer. Midl. Natur. 51:287-305.

-. 1961. Morphological and cytological variation in Helianthus petiolaris with notes on related species. Evolution 15:247-258.

1965. Sunflowers, weeds and cultivated plants, pp. 391-401. In H. G. Baker and G. L. Stebbins (eds.), The Genetics of Colonizing Species. Academic Press, N.Y.

. 1973. Introgression re-examined. Bot. Rev. 39:347-366.

Heiser, C. B., D. M. Smith, B. S. Clevenger, AND W. C. Martin. 1969. The North American Sunflowers (Helianthus). Mem. Torrey Bot. Club 22:1-218.

Hunt, W. G., ANd R. K. Selander. 1973. Biochemical genetics of hybridization in European house mice (Mus musculus). Heredity 31:11-33.

JaCkson, R. C., AND B. G. Murray. 1983. Colchicine induced quadrivalent formation in Helianthus: Evidence of ancient polyploidy. Theoret. Appl. Genet. 64:219-222.

Jansen, R. K., AND J. D. Palmer. 1987a. Chloroplast DNA from lettuce and Barnadesia (Asteraceae): Structure, gene localization, and characterization of a large inversion. Curr. Genet. 1:553-564.

- $1987 b$. A chloroplast DNA inversion marks an ancient evolutionary split in the sunflower family (Asteraceae). Proc. Nat. Acad. Sci. USA 84:58185822 .

Jorgensen, R. A., R. E. Cuellar, W. F. Thompson, AND T. A. Kavanagh. 1987. Structure and variation in ribosomal RNA genes of pea. Pl. Molec. Biol. 8:3-12. 
LAMB, T., AND J. C. Avise. 1986. Directional introgression of mitochondrial DNA in a hybrid population of tree frogs: The influence of mating behavior. Proc. Nat. Acad. Sci. USA 83:2526-2530.

Levin, D. A. 1963. Natural hybridization between Phlox maculata and $P$. glaberrima and its evolutionary significance. Amer. J. Bot. 50:714-719.

- 1975. Interspecific hybridization, heterozygosity and gene exchange in Phlox. Evolution 29: 37-51.

NEI, M. 1972. Genetic distance between populations. Amer. Natur. 106:283-292.

OliverI, A. M., AND S. K. JAIN. 1977. Variation in the Helianthus exilis-bolanderi complex. Madroño 24:177-189.

ORNDUFF, R. 1967. Hybridization and regional variation in Pacific Northwestern Impatiens (Balsaminaceae). Brittonia 19:122-128.

PALMer, J. D. 1982. Physical and gene mapping of chloroplast DNA from Atriplex triangularis and Cucumis sativa. Nucl. Acids Res. 10:1593-1605.

- 1985. Evolution of cpDNA and mtDNA in plants and algae, pp. 131-240. In R. J. Macintyre (ed.), Molecular Evolutionary Genetics. Plenum, N.Y.

1986. Isolation and structural analysis of chloroplast DNA, pp. 167-186. In A. Weissbach and $\mathrm{H}$. Weissbach (eds.), Methods in Enzymology. Academic Press, Orlando, FL.

Palmer, J. D., R. A. Jorgenson, AND W. F. Thompson. 1985. Chloroplast DNA variation and evolution in Pisum: Patterns of change and phylogenetic analysis. Genetics 109:195-213.

Palmer, J. D., C. R. Shields, D. B. Cohen, And T. J. ORTEN. 1983. Chloroplast DNA evolution and the origin of amphidiploid Brassica species. Theoret. Appl. Genet. 65:181-189.

PAlmer, J. D., AND D. Zamir. 1982. Chloroplast DNA evolution and phylogenetic relationships in Lycopersicon. Proc. Nat. Acad. Sci. USA 79:5006-5010.

Polans, N. O., N. F. Weeden, and W. F. Thompson. 1986. Distribution, inheritance and linkage relationships of ribosomal spacer length variants in pea. Theoret. Appl. Genet. 72:289-295.

Powell, J. R. 1983. Interspecific cytoplasmic gene flow in the absence of nuclear gene flow: Evidence from Drosophila. Proc. Nat. Acad. Sci. USA 80: 492-495.

RIESEBERG, L. H. 1987. A re-examination of introgression in Helianthus. Ph.D. Diss., Washington State Univ., Pullman.

RieseberG, L. H., AND D. E. Soltis. 1988. Origin of a weedy race of $H$. bolanderi: Biochemical evidence. Biochem. Syst. Ecol. In press.

Saghai-Maroof, M. A., K. M. Soliman, R. A. JorGENSEN, AND R. W. Allard. 1984. Ribosomal DNA spacer length polymorphism in barley: Mendelian inheritance, chromosomal location and population dynamics. Proc. Nat. Acad. Sci. USA 81 : 8014-8018.

Schilling, E. E., ANd C. B. Heiser. 1981. An infra- generic classification of Helianthus (Compositae). Taxon 30:393-403.

SElander, R. K., W. G. Hunt, AND S. Y. YANG. 1969. Protein polymorphism and genic heterozygosity in two European subspecies of the house mouse. Evolution 23:379-390.

Siegel, A., AND K. Kolacz. 1983. Heterogeneity of pumpkin ribosomal DNA. Pl. Physiol. 72:166-171.

SOlignaC, M., AND M. Monnerot. 1986. Race formation, speciation, and introgression within Drosophila simulans, $D$. mauritiana, and $D$. sechellia inferred from mitochondrial DNA analysis. Evolution 40:531-539.

Soltis, D. E., C. H. Haufler, D. C. Darrow, and G. J. GASTONY. 1983. Starch gel electrophoresis of ferns: A compilation of grinding buffers, gel and electrode buffers, and staining schedules. Amer. Fern J. 73:9-27.

Soltis, D. E., AND P. S. Soltis. 1986. Intergeneric hybridization between Conimitella williamsil and Mitella stauropetala (Saxifragaceae). Syst. Bot. 11: 293-297.

Soltis, P. S. 1985. Studies of genetic variation in an introgressive complex in Clarkia (Onagraceae). Ph.D. Diss., Univ. Kansas, Lawrence.

SPOLSKY, C., AND T. Uzzell. 1984. Natural interspecies transfer of mitochondrial DNA in amphibians. Proc. Nat. Acad. Sci. USA 81:5802-5805.

Stebins, G. L. 1959. The role of hybridization in evolution. Proc. Amer. Phil. Soc. 103:231-251.

. 1969. The significance of hybridization for plant taxonomy and evolution. Taxon 18:26-35.

Stebrins, G. L., AND K. Daly. 1961. Changes in the variation of a hybrid population of Helianthus over an eight-year period. Evolution 15:60-71.

Swofford, D. 1983. PAUP, Phylogenetic Analysis Using Parsimony. Illinois Nat. Hist. Surv., Urbana.

Swofford, D. L., AND R. B. Selander. 1981. BIOSYS-1. Univ. Illinois, Urbana.

SytSma, K. J., AND B. A. SchaAl. 1985a. Genetic variation, differentiation, and evolution in a species complex of tropical shrubs based on isozyme data. Evolution 39:582-593.

. 1985b. Phylogenetics of the Lisianthius skinneri (Gentianaceae) species complex in Panama utilizing DNA restriction fragment analysis. Evolution 39:594-608.

SytSMA, K. J., AND L. D. GotTlieb. 1986. Chloroplast DNA evidence for the origin of the genus Heterogaura from a species of Clarkia. Proc. Nat. Acad. Sci. USA 83:5554-5557.

Tilney-Bassett, R. A. E. 1978. The inheritance and genetic behavior of plastids, pp. 251-254. In J. T. O. Kirk and R. A. E. Tilney-Bassett (eds.), The Plastids. Elsevier, Amsterdam, Neth.

Zurawski, G., M. T. ClegG, and A. H. D. Brown. 1984. The nature of nucleotide sequence divergence between barley and maize chloroplast DNA. Genetics 106:735-749.

Corresponding Editor: S. N. Handel 